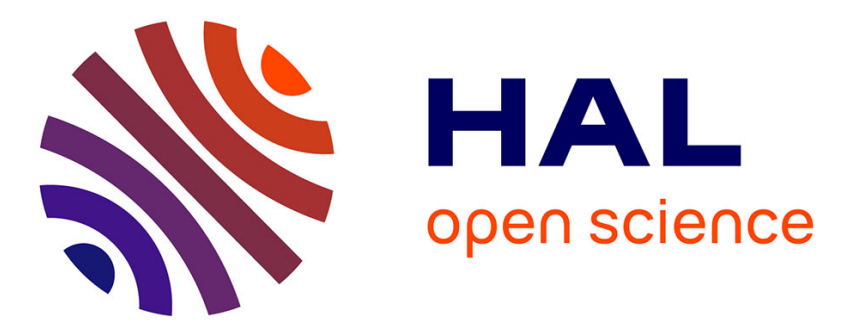

\title{
2D Charge Density Probing at Aluminum / SiN x Interface: a Sub-micrometric Investigation by Kelvin Probe Force Microscopy
}

C. Djaou, Christina Villeneuve-Faure, Laurent Boudou, Kremena Makasheva, G. Teyssedre

\section{To cite this version:}

C. Djaou, Christina Villeneuve-Faure, Laurent Boudou, Kremena Makasheva, G. Teyssedre. 2D Charge Density Probing at Aluminum / SiN x Interface: a Sub-micrometric Investigation by Kelvin Probe Force Microscopy. IEEE 2020 International Conference on Dielectrics, Jul 2020, Valencia (virtual ), Spain. pp. 451-454. hal-03003111v2

\section{HAL Id: hal-03003111 \\ https://hal.science/hal-03003111v2}

Submitted on 29 Nov 2020

HAL is a multi-disciplinary open access archive for the deposit and dissemination of scientific research documents, whether they are published or not. The documents may come from teaching and research institutions in France or abroad, or from public or private research centers.
L'archive ouverte pluridisciplinaire HAL, est destinée au dépôt et à la diffusion de documents scientifiques de niveau recherche, publiés ou non, émanant des établissements d'enseignement et de recherche français ou étrangers, des laboratoires publics ou privés. 


\title{
2D Charge Density Probing at Aluminum / $\mathrm{SiN}_{\mathrm{x}}$ Interface: a Sub-micrometric Investigation by Kelvin Probe Force Microscopy
}

\author{
C. Djaou, C. Villeneuve-Faure, L. Boudou, K. Makasheva and G. Teyssedre \\ LAPLACE, Université de Toulouse, CNRS, 118 Route de Narbonne, 31062 Toulouse Cedex 9, France
}

\begin{abstract}
Charge injection and transport mechanisms occurring at metal/dielectric interface may strongly impact devices performance and reliability. However, these phenomena remain partially understood, mainly due to the lack of adapted characterization tools. In this paper, we propose an investigation of the charging behavior at the $\mathrm{Al} / \mathrm{SiN}_{\mathrm{x}}$ interface using Kelvin Probe Force Microscopy (KPFM). Indeed, KPFM measurements permit to probe space charge density with a sub micrometric resolution. Results presented here emphasize that electrons and holes are injected and trapped close to cathode and anode, respectively. The charge clouds remain stacked to the interface $(2-3 \mu \mathrm{m})$. Moreover, the amount of injected charges increases with the applied bias. The injected electrons and holes follow the same dissipation mechanism in time after bias removal.
\end{abstract}

\section{INTRODUCTION}

Space charge injection at metal/dielectric interface and transport in dielectric materials are the main causes of failure in many electronic devices. Such trouble leads to a loss of control in the system, requiring a premature replacement. As a result, issues as leakage current or dielectric breakdown in CMOS devices with thin gate dielectric film [1], or electrostatic sticking of the mobile membrane switching in radio-frequency microelectromechanical systems with electrostatic actuation [2], could occur. In this context, metal/dielectric interfaces play a key role. Consequently, the understanding of charge build-up and transport in thin dielectric materials is decisive for improving their performance and reliability. Classical space charge probing methods [3] present generally no lateral resolution. Even though the focus light intensity modulation method (FLIMM) [4] allows 3D space charge probing, its lateral resolution, of few microns, is incompatible with investigation of physical mechanisms occurring close to the interface.

To provide desired information, methods derived from Atomic Force Microscopy (AFM) were proposed to probe space charge density with sub-micrometer resolution. In this case, charge is injected using bias voltage applied to lateral electrodes embedded within the dielectric and the related surface potential is followed using Kelvin Probe Force Microscopy (KPFM) [5-8]. These works mainly address the charge injection phenomenon in a qualitative way without determining charge density profiles. Recently, a numerical procedure based on solution of the Poisson's equation was proposed to extract the space charge density profiles between two lateral electrodes from the recorded surface potential [911]. However, a better understanding of the mechanisms underlying the charge injection and transport at metal/dielectric interface is needed.

This study aims to investigate charge injection and trapping phenomena at aluminum/ $\mathrm{SiN}_{\mathrm{x}}$ interface. To that end, the charge is injected from Al-electrodes of lateral electrodes structures, and the surface potential evolution is probed by using Frequency Modulation KPFM (FM-KPFM), as this mode appears more sensitive to trapped charge than Amplitude Modulation KPFM [11]. Charge density profiles are extracted from the surface potential measurements to describe the electric field influence on the charge cloud.

\section{EXPERIMENTS}

\section{A. Lateral electrodes processing}

The used lateral electrode devices consisted in MIM (MetalInsulator-Metal) structures composed of $\mathrm{Al}$ electrodes with inter-electrode separation of $\mathrm{W}=25 \mu \mathrm{m}$, embedded in silicon nitride $\left(\mathrm{SiN}_{\mathrm{x}}\right)$ dielectric films. The $\mathrm{SiN}_{\mathrm{x}}$ dielectrics were $300 \mathrm{~nm}$-thick. They were deposited by high frequency plasma enhanced chemical vapor deposition [12] on a low resistivity silicon substrate. $70 \mathrm{~nm}$-thick $\mathrm{Al}$ electrodes were processed by photolithography following a process described elsewhere [10]. Finally, a $5 \mathrm{~nm} \mathrm{SiN}_{\mathrm{x}}$ passivation layer was deposited over the embedded electrodes to avoid discharges during polarization. The resulting MIM structure is schematically presented in top-view (Fig. 1.a) and in cross-view (Fig. 1.b).

\section{B. Surface potential measurement}

A Bruker Multimode 8 set up was used to investigate space charge injection and transport. Surface potential measurements were performed using Frequency Modulated-KPFM (FMKPFM) in a single-pass configuration with PtIr-coated Si tips (spring constant $\mathrm{k}$ of around $3 \mathrm{~N} / \mathrm{m}$ ).

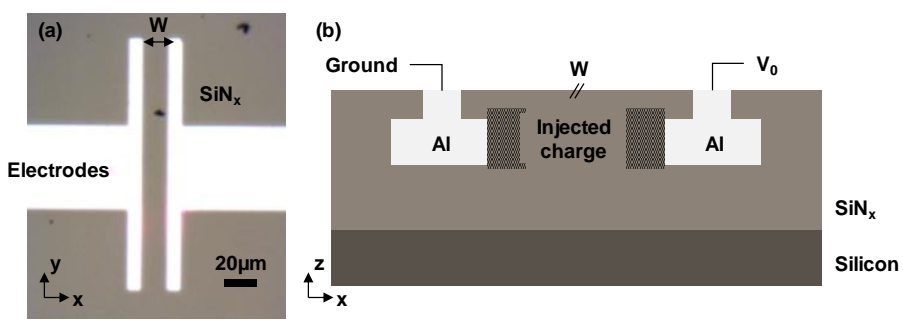

Fig. 1. (a) Optical microscopy top-view image of the lateral electrode device. (b) Cross-view scheme of the electrode polarization configuration. 
For charge injection, the right Al-electrode was polarized using a DC-voltage $\mathrm{V}_{0}$ whereas the left electrode was grounded (Fig. 1.b). The silicon substrate backside was also set to the ground. Voltage $\mathrm{V}_{0}$, ranging from $+10 \mathrm{~V}$ to $+40 \mathrm{~V}$ (by steps of $10 \mathrm{~V}$ ), was applied during $50 \mathrm{~min}$. After charge injection, the electrodes were grounded and the surface potential was probed by FM-KPFM.

\section{Charge density extraction method}

To determine the charge density profiles $\rho(x)$, the surface potential profile $V_{s}(x)$ was derived using the Second Derivative Method (SDM) already reported in literature [11]:

$$
\rho(x)=-\varepsilon_{0} \varepsilon_{\mathrm{r}} d^{2} V_{\mathrm{s}} / d x^{2}
$$

where $\varepsilon_{0}$ is the vacuum permittivity, $\varepsilon_{\mathrm{r}}$ is the relative permittivity of silicon nitride $\left(\varepsilon_{\mathrm{r}}=7.5\right)$ and $x$ is the lateral position. The derivation was obtained using a step $d x$ of $136 \mathrm{~nm}$ which is actually twice the measurement step.

\section{RESUlTS AND DisCUSSION}

\section{A. Surface potential measurement}

Fig. 2.a and 2.b show the topography and the surface potential mapping after applying $30 \mathrm{~V}$ during $50 \mathrm{~min}$. Surface potential profiles at different positions (different y-axis) are shown in Fig. 2.c. Two peaks have been recorded, a positive one close to the anode and a negative one close to the cathode, ascribed to the injection of holes and electrons, respectively. Comparison of the potential profiles recorded at different ypositions (Fig. 2.c) shows negligible differences. In the following, the surface potential profile will be presented at only one y-position.
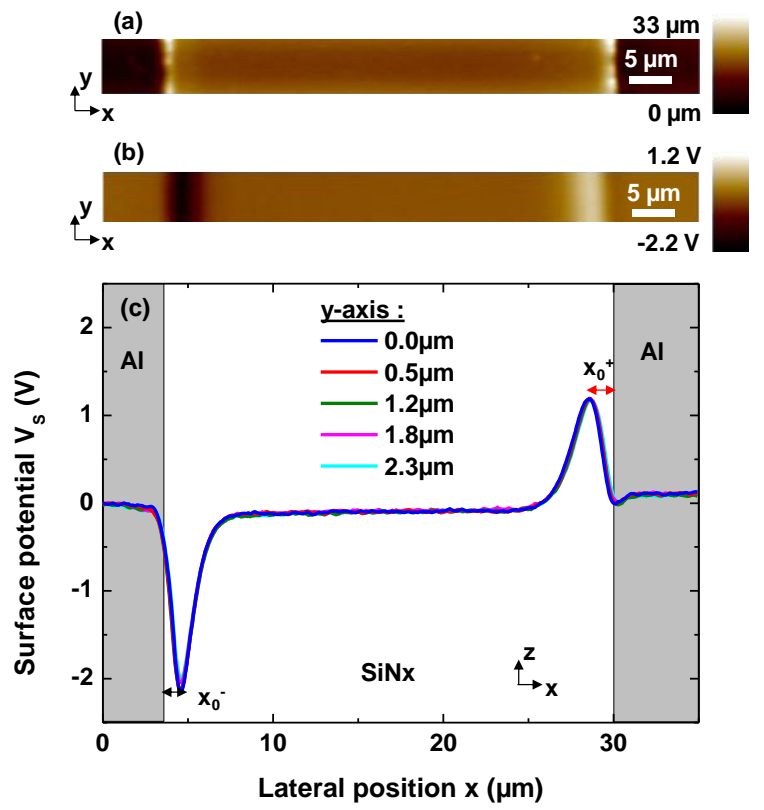

Fig. 2. (a) Topography and (b) surface potential profile maps probed by FMKPFM after electrode polarization at $30 \mathrm{~V}$ during $50 \mathrm{~min}$. (c) Potential profiles extracted from surface potential map at different y-positions.
To investigate charges injection and decay mechanisms, four parameters are extracted from the surface potential profiles $\mathrm{V}_{\mathrm{s}}(\mathrm{x})$ for the positive and negative peaks:

- the surface potential maximum $\mathrm{V}_{\max }$ (labelled $\mathrm{V}_{\max }{ }^{+}$for the positive peak and $\mathrm{V}_{\max }{ }^{-}$for the negative peak);

- the area under the peak;

- the FWHM (Full Width at Half Maximum) which reflects the spreading of charges in the dielectric;

- the position $x_{0}{ }^{+}$of the maximum of the positive peak to the right $\mathrm{Al} / \mathrm{SiN}_{\mathrm{x}}$ interface;

- the position $x_{0}{ }^{-}$of the maximum of the negative peak to the left $\mathrm{Al} / \mathrm{SiN}_{\mathrm{x}}$ interface.

\section{B. Charge injection behavior}

The evolution of $\mathrm{V}_{\max }$ and the area under the peak is depicted on Fig. 3.a. The results show that $\mathrm{V}_{\max }$ and the area increase with the same rate as the applied bias $\mathrm{V}_{0}$ used for charge injection. Moreover, the increase is more important for the negative potential peak.

The evolution of FWHM and $x_{0}$ (Fig. 3.b.) shows that the peak widths decrease with increasing the applied bias $\mathrm{V}_{0}$ for both polarities, whereas the maximum peak positions remain unchanged and stacked to the $\mathrm{Al} / \mathrm{SiN}_{\mathrm{x}}$ interface at about $2 \mu \mathrm{m}$ for the positive peak and $3.5 \mu \mathrm{m}$ for the negative peak.
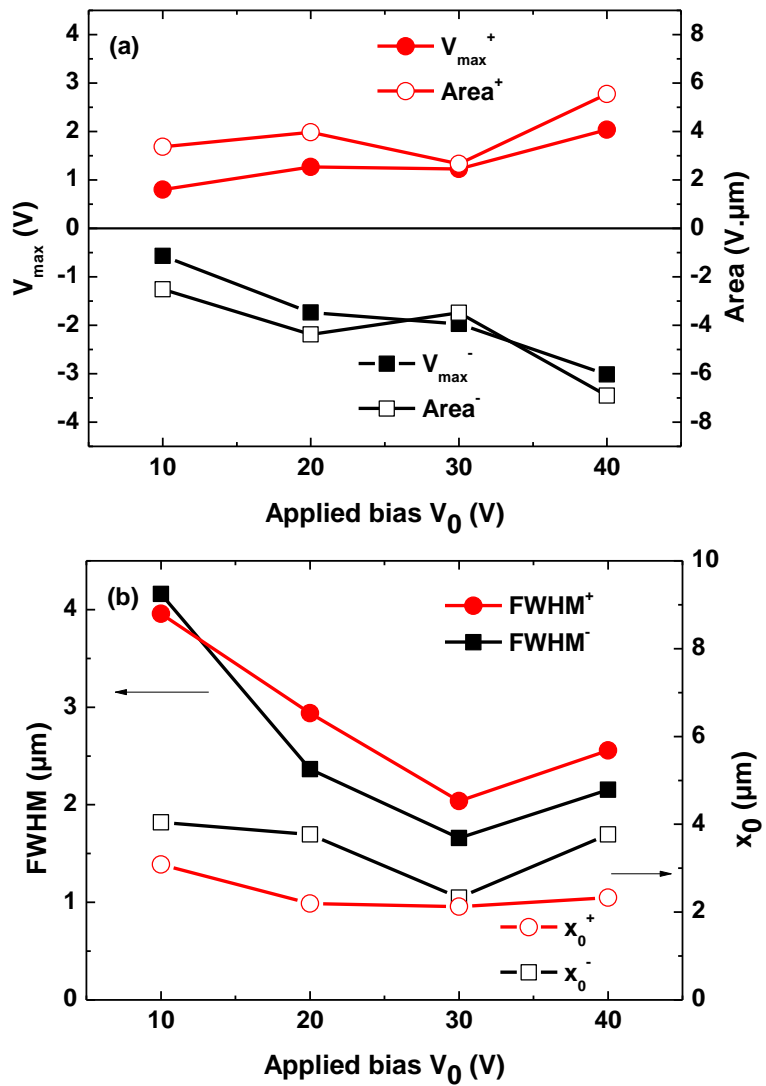

Fig. 3. (a) Maximum potential and area of the charge peaks (b) FWHM and metal/charge peak-maximum distances. 
To go further into the charge injection mechanism investigation, the charge density profile was extracted from the surface potential profile using the SDM method. The resulting charge density profile obtained after charge injection at $30 \mathrm{~V}$ during $50 \mathrm{~min}$ is depicted on Fig. 4.a.

The obtained charge profile emphasizes that the negative charges are trapped close to the cathode and positive charges are trapped close to the anode (Fig. 4.a). Moreover, the related image charges are revealed at each metal electrode. The charge peaks are narrow and remain stacked to the electrodes at $2 \mu \mathrm{m}$ for the positive peak and $3.5 \mu \mathrm{m}$ for the negative peak, the same as for the surface potential shown on Fig. 3.b. No significant amount of charges is measured in the middle of the inter-electrode space. The observed oscillations on the charge density profile are due to the noise on the surface potential profile measurements. For charge injection at $10 \mathrm{~V}$ the ratio signal over noise is too low and does not allow extraction of the charge density profile.

The positive and negative charge density peaks were fitted to Gaussian functions to extract the maximum density $\rho_{0}$, and the FWHM. Results are summarized on Fig. 4.b. These results show a narrow distribution of the charge densities with FWHM varying between $600 \mathrm{~nm}$ and $1 \mu \mathrm{m}$. However, the applied bias and the related electric field seem to influence differently the electron and the hole densities.
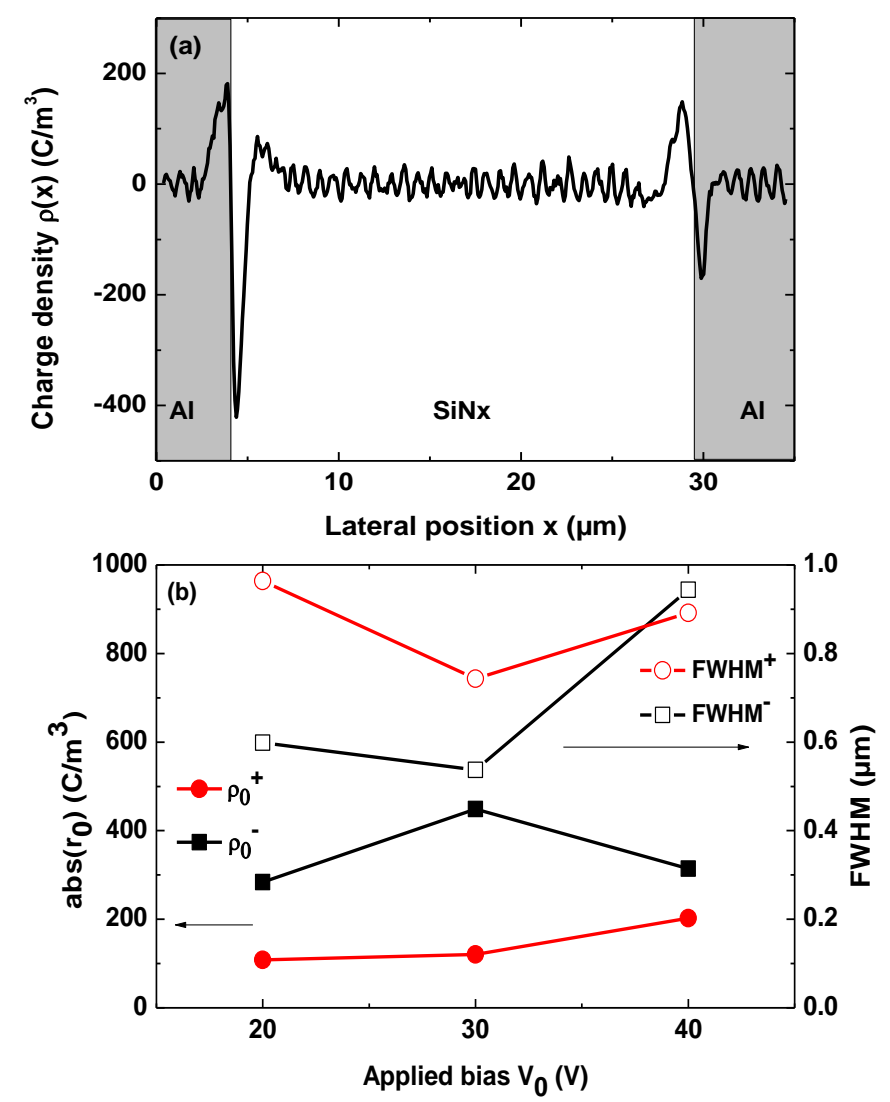

Fig.4. (a) Charge density profile obtained for charge injection at $30 \mathrm{~V}$ during 50min. (b) Evolution of the absolute value of maximum charge density $\rho_{0}$ with the applied bias $V_{0}$.
Indeed, concerning the holes, the maximum charge density increases with the applied bias whereas the FWHM remains constant. The negative peak shows opposite behavior. Its FWHM increases with the applied bias whereas the maximum charge density remains constant.

The increase of charge density is more important for electrons, as predicted by the energy diagram for an $\mathrm{Al} / \mathrm{SiN}_{\mathrm{x}}$ interface. Schottky energy barriers of $2.1 \mathrm{eV}$ for electrons and $3.2 \mathrm{eV}$ for holes, have been found considering the alignment, at the metal/dielectric interface, of the Fermi level of the Alelectrodes with the Charge Neutrality Level (CNL) of the $\mathrm{SiN}_{\mathrm{x}}$ film with pinging parameter $S=0.66$ obtained for the studied here dielectric [12-13].

\section{Decay}

In order to observe the charge dynamics, surface potential measurements were performed by scanning over a single line for $60 \mathrm{~min}$ after the charge injection. The acquired profiles are presented in Fig. 5. A decrease of the maximum potential and a slight peak broadening were observed for the first $10 \mathrm{~min}$.

To investigate accurately the decay dynamic, the maximum potential and the area were normalized by their initial values. They are depicted on Fig. 6.a. The maximum potential and area of both peaks decrease in time following an exponentiallike law. The initial potential value is reduced by about $60 \%$ after $1 \mathrm{~h}$ of discharge for both positive and negative peaks. This dynamical behavior is comparable to the one obtained for microscale contact charging in $\mathrm{SiN}_{\mathrm{x}}$ dielectrics in case of dissipation in the volume [14]. Peak broadening compared to initial FWHM and peak position are depicted on Fig. 6.b. These results emphasize a small lateral spreading, which is more important for the positive carriers. Moreover, the peak position remains constant suggesting that the injected charges remain localized at the same position in time. The same tendency is obtained for all injection biases, showing that the electrons and the holes undergo the same dissipation dynamics.

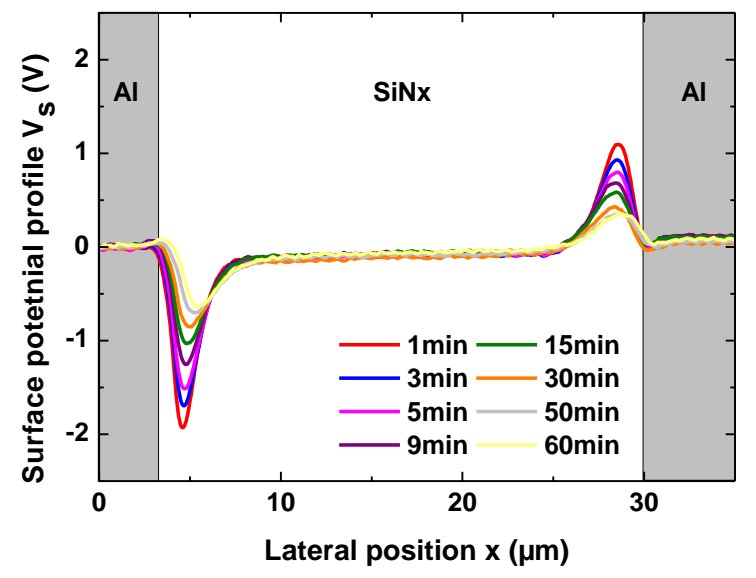

Fig. 5. Potential profile decay with time after injection using an applied bias of $30 \mathrm{~V}$ during 50 minutes. 

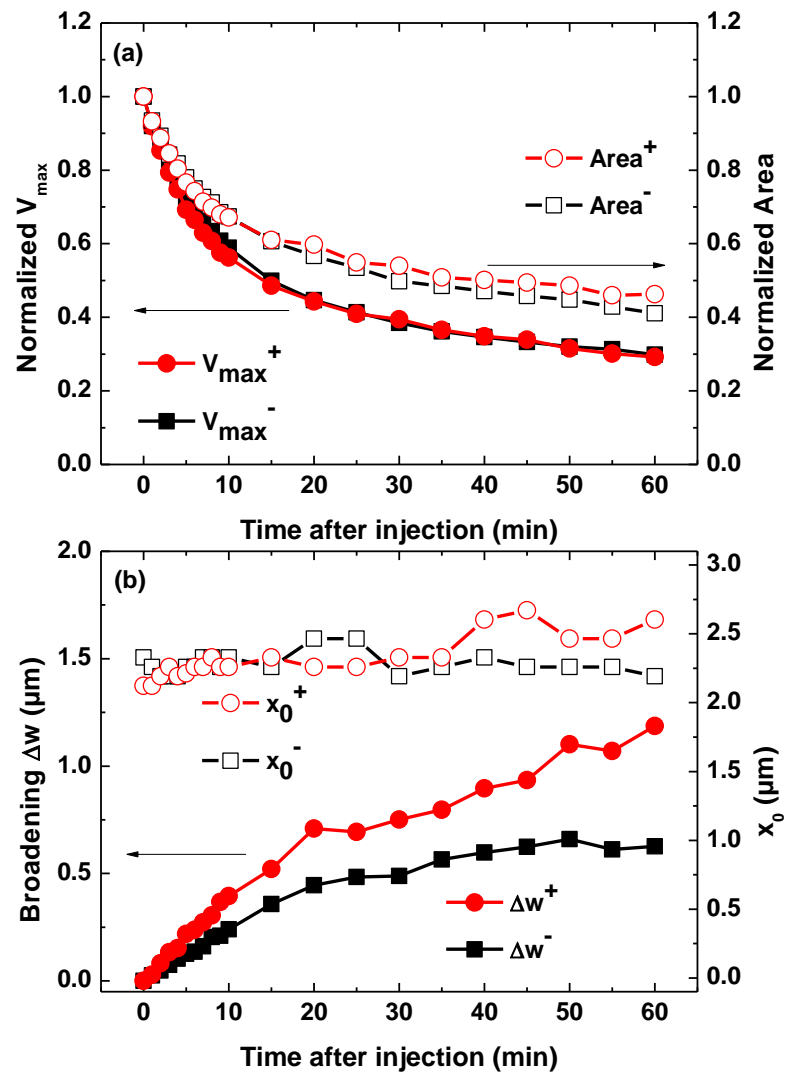

Fig. 6. (a) Evolution of the maximum potential and area normalized, by the initial values, as function of time after injection. (b) Evolution of the peak broadening, compared to the initial FWHM, and the peak position as function of time after injection. Injection for $50 \mathrm{~min}$ at $30 \mathrm{~V}$.

\section{CONCLUSION}

In this paper, we have presented an investigation of the charge injection and transport at the $\mathrm{Al} / \mathrm{SiN}_{\mathrm{x}}$ interface by using a device with embedded metal electrodes in a dielectric layer. Surface potential measurements by FM-KPFM permitted to extract charge density profiles with a submicron resolution, even though the charges are situated close to the electrode. The obtained results show that the negative charges are injected close to the cathode and the positive charges close to the anode and remain stacked to the $\mathrm{Al} / \mathrm{SiN}_{\mathrm{x}}$ interface (2-3 $\mu \mathrm{m})$ regardless the applied voltage and the time for decay after voltage removal. The amount of injected charges increases with the applied electric field, and this increase is more important for electrons. This finding is consistent with the alignment of the Fermi level of Al-electrodes with the CNL of the $\mathrm{SiN}_{\mathrm{x}}$ dielectric, situated in between the conduction and valence bands. After injection, the electrons and holes follow the same decay dynamics which is mainly ruled by dissipation mechanism at the electrodes or in the volume of the dielectric towards the substrate.

The next step of this work consists in investigation of other metal/dielectric interfaces in order to identify the impact of the metal work function on the electrons and holes on charging dynamics.

\section{ACKNOWLEDGMENT}

Research carried out as part of the IDEX Actions Thématiques Stratégiques - ATS 2015 de l'Université de Toulouse, projet SEPHIR (2016-066-CIF-D-DRVD). This work was partly supported by the French RENATECH network.

\section{REFERENCES}

[1] A. Kerber, E. Cartier, R. Degraeve, P.J. Roussel, L. Pantisano, T. Kauerauf, G. Groeseneken, H.E. Maes and U. Schwalke, "Charge trapping and dielectric reliability of $\mathrm{SiO}_{2}-\mathrm{Al}_{2} \mathrm{O}_{3}$ Gate stacks with TiN electrodes," IEEE Trans. Electron Dev., vol. 50, p.1261, 2003.

[2] A. Witvrouw, H.A.C. Tilmans and I. De Wolf, "Materials issues in the processing, the operation and the reliability of MEMS," Microelectron. Eng., vol. 76, p.245, 2004.

[3] N.H. Ahmed and N.N. Srinivas, "Review of space charge measurements in dielectrics," IEEE Trans. Dielectr. Electr. Insul., vol. 4, pp.644-656, 1997.

[4] A. Petre, C.-D.Pham, D.Marty-Dessus and L.Berquez "Threedimensional space charge cartographies by FLIMM in electron irradiated polymers," J. Electrostatics, vol. 67, pp.430-434, 2009.

[5] T. Okamoto, S. Kitagawa, N. Inoue and A. Ando, "Electric filed concentration in the vicinity of the interface between anode and degraded BaTiO3-based ceramic capacitor," Appl. Phys. Lett., vol. 98, p. 072905, 2011.

[6] M. Jacquith, E.M. Muller and A. Marohn, "Time-resolved electrostatic force microscopy of charge trapping in polycrystalline pentacene," $J$. Phys. Chem. B, vol. 111, p. 7711, 2007.

[7] T.N. Ng, W.R. Silveira and J.A. Marohn, "Dependence of charge injection on temperature, electric field, energetic disorder in an organic semiconductor," Phys. Rev. Lett., vol. 98, p. 066101, 2007.

[8] B. Martin and H. Kliem, "Space charge measurements with the scanning Kelvin Probe," IEEE Trans. Dielec. Electr. Insul., vol. 15, p. 560, 2008.

[9] K. Faliya, H. Kliem and C.J. Dias, "Space charge measurements with Kelvin Probe force microscopy," IEEE Trans. Dielec. Electr. Insul., vol. 24, p. 1913, 2017.

[10] F. Mortreuil, C. Villeneuve-Faure, L. Boudou, K. Makasheva and G. Teyssedre, "Charge injection phenomena at the metal/dielectric interface investigated by Kelvin probe force microscopy," J. Phys. D. Appl. Phys., vol. 50, p. 175302, 2017.

[11] C. Villeneuve-Faure, L. Boudou, K. Makasheva, and G. Teyssedre, "Methodology for extraction of space charge density profiles at nanoscale from Kelvin probe force microscopy measurements," Nanotechnology, vol. 28, p. 505701, 2017.

[12] J. Robertson, "Band offsets of wide-band-gap oxides and implications for future electronic devices," J. Vac. Sci. Technol. B., vol. 18, pp. 1785$1791,2000$.

[13] C. Villeneuve-Faure, K. Makasheva, L. Boudou, and G. Teyssedre, "Charge injection in thin dielectric layers by atomic force microscopy: influence of geometry and material work function of the AFM tip on the injection process," Nanotechnology, vol. 27, p. 245702(10pp), 2016.

[14] U. Zaghloul, G. J. Papaioannou, F. Coccetti, P. Pons, and R. Plana, "A systematic reliability investigation of the dielectric charging process in electrostatically actuated MEMS based on Kelvin probe force microscopy," J. Micromechanics Microengineering, vol. 20, p. 064016, 2010. 